\title{
Hospital surge capacity management of methanol poisoning in an Iranian hospital: A case-study in Rafsanjan, Iran
}

\author{
Khodadadizadeh A, $\mathrm{MSc}^{1}$, Jahangiri $\mathrm{K}, \mathrm{PhD}^{2 *}$, Sharifian $\mathrm{S}, \mathrm{MSc}^{3}$ \\ 1- Faculty Member, School of Nursing, Rafsanjan University of Medical Sciences, Rafsanjan, Iran. PhD Student in Health in \\ Emergency \& Disaster, Shahid Beheshti University of Medical Sciences, Tehran ,Iran, 2- Associate Prof., Dept. of emergencies, \\ school of Health, Safety and environment, Shahid Beheshti University of Medical Sciences, Tehran, Iran. 3- PhD Student in \\ Health in Emergency \& Disaster, Shahid Beheshti University of Medical Sciences, Tehran, Iran.
}

\begin{abstract}
Received: December 2015, Accepted: February 2016

Background: Hospital surge capacity (HSC) is essential to the successful management of expected consequences of disasters and mass casualty incidents (MCIs). In MCIs, an unanticipated number of sick or injured people refer to the hospital, and thus, the hospital is faced with a significant increase in the burden of necessary activities and services. Therefore, managing the process in order to meet patients' needs is critical. Mass poisoning is an emergency event that requires HSC. The aim of the present study was to analyze the activities performed to manage poisoning caused by oral consumption of methanol in the summer of 2013 in Rafsanjan, Iran.

Materials and Methods: This was an empirical case study consisting of various stages. The research environment was one of the teaching hospitals in Rafsanjan. The target population included emergency officials of the incident command system (ICS) and emergency operation center (EOC), and the Deputy of Health in Rafsanjan University of Medical Sciences. Data were collected through review of documentation, internet resources, observation, and deep interviews with officials. Framework Analysis was used for the analysis of qualitative data.

Results: During this incident, 694 individuals referred to the hospital within 1 day; 361 patients were treated in Rafsanjan and 333 patients were referred for treatment to other cities (Kerman, Zarand, Shahr Babak, Sirjan, Bardsir, and Yazd). In terms of HSC management, communication was better in the 4Cs than other factors. In the 4Ss, the performance of staff was acceptable, and in the 3Ts, the treatment and transference of poisoned patients were evaluated as satisfactory and acceptable, respectively.

Conclusions: According to the results of this study, HSC in the event of methanol poisoning is inevitable. Therefore, attention to and preparation for this issue in the response phase is very important. Hospitals should identify their capacities in order to take appropriate action toward the prevention of, preparation for, and response to an event.
\end{abstract}

Keywords: Hospital, Surge Capacity, Methanol, Poisoning

\section{Introduction}

Usually after an emergency or disaster, the large number of injured people leads to casualty influx in health centers. In such situations, hospital surge capacity (HSC) is essential to the successful management of mass casualty incidents (MCIs) (1). HSC is the ability of a hospital to rapidly adjust to the increased demand for hospital health services. This situation generally occurs after natural and manmade disasters or any incident which causes mass casualties (2). Therefore, when our need for health services increase to higher than the available resources and there is an imbalance

\footnotetext{
* Corresponding author: Katayoun Jahangiri, Dept. of emergencies, school of Health, Safety and environment, Shahid Beheshti University of Medical Sciences, Tehran, Iran

Email: katayounjahangiri@yahoo.com
} 
between demand and supply, HSC will emerge $(2,3)$. In such circumstances, optimal use of hospital facilities, resource mobilization, triage system, and clinical and managerial interventions are very important in order to control or stabilize the demand, strengthen the referral system and the capacity of health care outside the hospital, forecast and determine alternative treatment sites, and coordinate all stakeholders and surveillance system activation (4).

The HSC depends on 4Cs including command, control, communications, and coordination, 4Ss including space, staff, stuff, and specialty, and 3Ts including triage, treatment, and transportation. HSC is achieved through the provision of the 4Cs, 4Ss, and 3Ts (2). Therefore, HSC includes physical space, organizational structure, medical staff, auxiliary equipment, support (e.g., nutrition and mental health), information system, and medicines (5). In HSC, knowledge of requirements of patient care is necessary (6). Evidently, efficient response to casualty influx depends on appropriate resource allocation (workforce and equipment). Resources should be allocated in a way suitable for the treatment of the many victims and patients who refer to the hospital after an emergency (7). In large-scale emergencies and disasters, it is very difficult to provide services to patients (8). Thus, the ability to respond to mass casualties should be included in hospital preparedness plan for disasters which disrupt the daily activities of the hospital. HSC has another category the components of which include staff, subject, structure, and system (2). It is not only important to increase the capacity of hospital services, but also the mechanism of care due to impact of events $(9,10)$. This mechanism can control the situation in time of a disaster and emergency (11). In MCIs, the demand for health and health care facilities suddenly increases (12). Mass poisoning that can be intentional or unintentional, is an example of situations in which hospitals must increase their capacity. Poisoning may occur through inhalation like chemical inhalation, oral intake like food poisoning, or dermal intake like absorption of toxins and injection of drugs (in drug users). In this study, food poisoning caused by drinking alcohol containing methanol, was investigated. Methanol poisoning is a medical emergency that can cause acute poisoning in a large number of people (13). Methanol is absorbed from the gastrointestinal tract after oral administration and leads to methanol poisoning; $30 \mathrm{ml}$ of methanol can cause permanent blindness and 30 to $240 \mathrm{ml}$ can be potentially fatal (14). In the body, alcohol containing methanol will transform into metabolic toxins such as formic acid during the metabolic process, and then, metabolic acidosis, due to accumulation of formate, can cause tissue hypoxia. High concentration of formate and lactate will cause acidosis, and in turn, some clinical symptoms such as headache, dizziness, nausea, vomiting, and abdominal pain. In advanced phases, visual disturbances, gastrointestinal bleeding, seizures, pancreatitis, and coma will occur. Intravenous administration of sodium bicarbonate to control metabolic acidosis, ethanol as an antidote, and fomepizole and folic acid or folinic acid to prevent the conversion of methanol to formate and rapid conversion of formate to water and carbon dioxide are the treatment methods for methanol poisoning (15).

This study investigated the illegal distribution of methanol in Rafsanjan, Iran, on 29/05/2013 that led to the transference of 694 casualties to Ali-ibn Abi Talib Hospital (with mild to severe symptoms) and caused HSC. The aim of this study was to investigate the challenges of managing SC in response to this emergency in the hospital and determine the strengths and weaknesses of the system to improve the system for similar situations. 


\section{Material and Methods}

This empirical, qualitative, case study was implemented in 5 phases by reviewing recourses. The research environment was the Ali-ibn Abi Talib Hospital in Rafsanjan. Data collection in different phases was implemented through a variety of methods such as observation, in-depth interviews, and review of documents, texts, and the internet. In the first phase, a literature review was performed using keywords such as hospital surge capacity and mass casualty incidence. As a result, 50 related articles were extracted and among them 24 papers were selected. In the second phase, viewing experiences by researchers were classified. In the third phase, a qualitative study was designed, the participants of which were the officials of the incident command system (ICS) and emergency operation center (EOC) and the Deputy of health of the University of Rafsanjan. The data were collected through 10 in-depth interviews, each one lasting 15-20 minutes.

In the fourth phase, Framework Analysis was used for data analysis. Framework Analysis consists of 5 steps including familiarization, identification of a thematic framework, indexing, charting, and mapping and interpretation. The 4 criteria of acceptability, transferability, reliability, and verifiability were used to ensure the validity, accuracy, and reliability of the data. In the fifth phase, some strategies were proposed to respond to such events.

\section{Result}

Rafsanjan is a city in Kerman Province. According to the 2012 census, its population was 151,420 . This city is adjacent to Zarand from the North, Shahr Babak from the West, Sirjan from Southwest, Bardsir from the South, and Kerman from the East. The distance between Rafsanjan and Kerman is $110 \mathrm{Km}$ (16). Rafsanjan has three hospitals, Ali-ibn Abi Talib,
Moradi, and Niknafas Maternity Hospital. The Ali-ibn Abi Talib Hospital was founded in 1987 and has 300 approved beds. This hospital has 200 active beds and is located in the south of the city. This hospital has different departments such as surgical wards for men and women, the internal and neurosurgical wards, pediatrics ward, neonatal ward, intensive care unit (ICU), coronary care unit (CCU), neonatal intensive care unit (NICU), dialysis unit, cardiac intensive care unit (CICU), angiography, operating room, emergency department, and etcetera. This hospital can cover a population of 200,000 individuals. The hospital has four entrance and exit doors. The doors on the East side of the hospital are for traffic of administrative personnel, doctors, and students. The door on the Northwest side of the hospital is for the entrance of patients. The emergency department includes trauma emergency, inpatient and outpatient emergency, and triage. This department has the capacity for providing services to 80-90 inpatients and 240-270 outpatients in 24 hours (17).

The first casualty due to alcohol intoxication (chronology of the events listed in table 1) was brought to the emergency department of Ali-ibn Abi Talib Hospital by ambulance at 21:37 p.m. on $29 / 05 / 2013$. After emergency treatment by the health team and interviews with the patient's family, alcohol poisoning and methanol poisoning were detected. On 30/05/2013, the other 2 casualties were brought to the emergency department at 7:38 a.m. Despite receiving treatment, one of them died and the other was hospitalized. A new case was also referred to the department at 8:45 a.m. At this point, the medical team such as physicians, emergency medicine doctors, and triage personnel predicted that the number of casualties might increase, so they decided to inform the EOC of the university. The number of casualties was growing. At 12 a.m., a meeting was held between law enforcement officers, the attorney 
general of province, head of the university and hospital, and the provincial governor. EOC was activated at 13 p.m. The hospital staff were called to the emergency department at 13:15 p.m. The health care team consisted of 4 emergency specialists, and 4 emergency physicians, nurses of the emergency department, and disaster teams.

Table 1: The chronology of the methanol poisoning incident

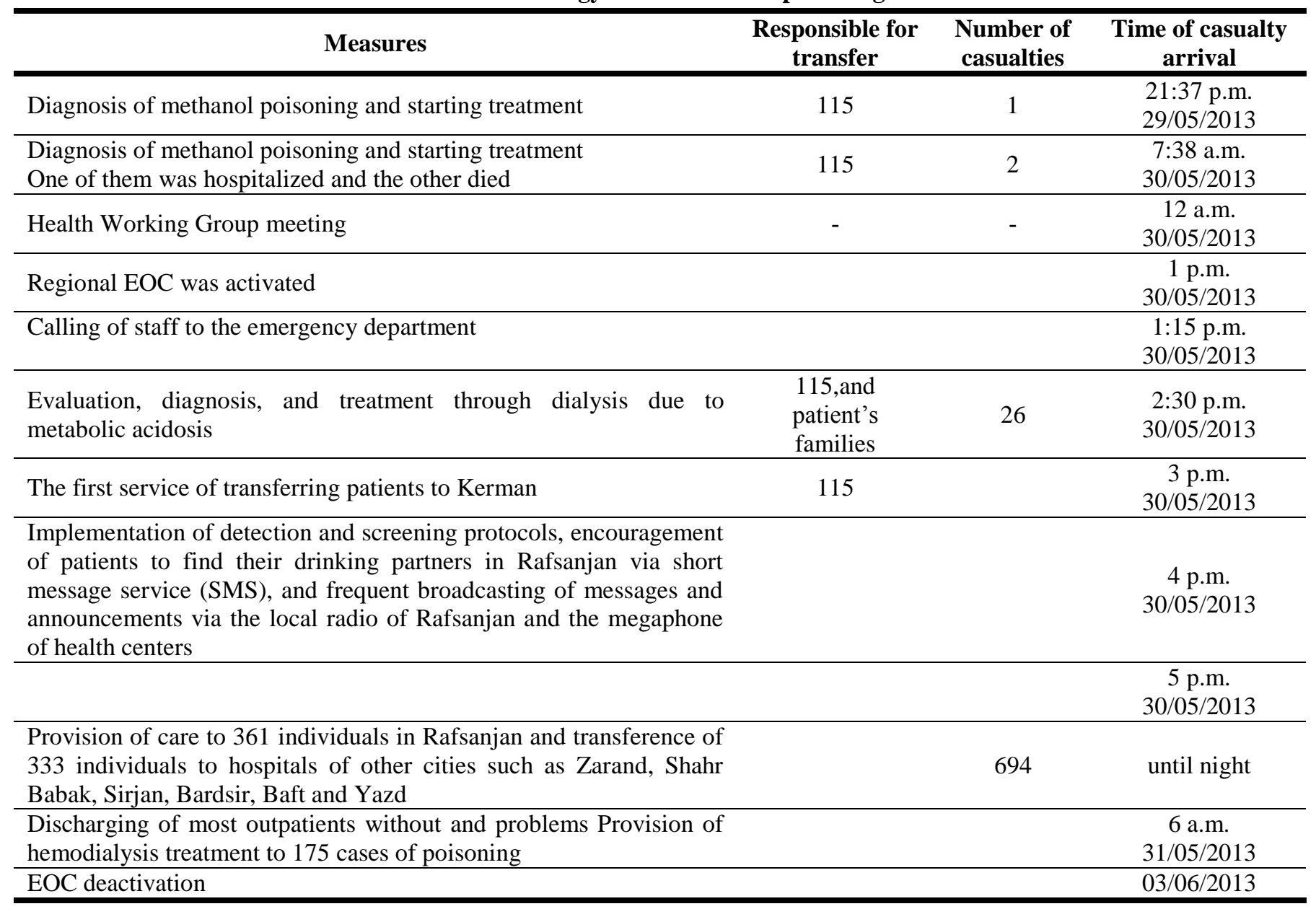

EOC: Emergency operation center

At 14:30 p.m., the number of casualties rose to 26 individuals. Many of them were suffering from severe metabolic acidosis and required dialysis. Therefore, the hospital did not have the capacity for the growing number of casualties. At 15 p.m., some patients were referred to other facilities. At 16 p.m., a screening protocol was activated through encouraging the patients to find their drinking partners and inform them via short message service (SMS), and making announcements through the local radio of Rafsanjan and via the local public health center.
After starting the screening protocol, the number of patients in the emergency department of Aliibn Abi Talib Hospital (even with minor symptoms) increased (18). After this valuable early warning and public announcement, all 24 ambulances of the emergency center and 3 bus ambulances were used. All operations were controlled by the Incident Commander of the ICS.

After the public announcement, the number of casualties rose to 694 individuals. Thus, 361 individuals received care in Rafsanjan, and 333 
individuals were transferred to hospitals of other cities such as Zarand, Shahr Babak, Sirjan, Bardsir, Baft, and Yazd. The main indication for hemodialysis (HD) was resistant metabolic acidosis; therefore, 175 individuals received hemodialysis. The number of inpatients and outpatients was 194 and 500, respectively. In addition, care was provided by 4 emergency specialists, and 4 emergency practitioners, nurses of the emergency department, and disaster teams. However, 8 patients died. Except serum of deceased cases, there was no evidence of the level of methanol in serum (18). Regarding HSC, the strengths and weaknesses of the hospital are reported below.

Table 2: Characteristics of surge capacity from the perspective of $4 \mathrm{Cs}$ in the hospital

\begin{tabular}{|c|c|c|c|c|c|c|c|}
\hline \multicolumn{2}{|c|}{ Coordination } & \multirow{2}{*}{\multicolumn{2}{|c|}{$\begin{array}{l}\text { Communication } \\
-\quad+\end{array}$}} & \multicolumn{2}{|c|}{ Control } & \multicolumn{2}{|c|}{ Command } \\
\hline- & + & & & - & + & - & + \\
\hline $\begin{array}{l}\text { According to the } \\
\text { hospital } \\
\text { protocols, the } \\
\text { HICS was not } \\
\text { well } \\
\text { coordinated. }\end{array}$ & $\begin{array}{l}\text { Coordination } \\
\text { in ICS was } \\
\text { satisfactory. }\end{array}$ & & $\begin{array}{l}\text { The } \\
\text { reporting } \\
\text { and } \\
\text { recording } \\
\text { of the } \\
\text { health team } \\
\text { in the ICS } \\
\text { was } \\
\text { satisfactory. }\end{array}$ & $\begin{array}{l}\text { There was no } \\
\text { plan for } \\
\text { management of } \\
\text { VIPs such as } \\
\text { representatives } \\
\text { of the provincial } \\
\text { governor and } \\
\text { attorney, police, } \\
\text { and the press and } \\
\text { media, and this } \\
\text { caused some } \\
\text { problems in } \\
\text { providing } \\
\text { services. }\end{array}$ & $\begin{array}{c}\text { The } \\
\text { security } \\
\text { department } \\
\text { of the } \\
\text { hospital } \\
\text { functioned } \\
\text { well. }\end{array}$ & $\begin{array}{l}\text { The duties of } \\
\text { the manager } \\
\text { of each } \\
\text { section were } \\
\text { not clear and } \\
\text { this caused } \\
\text { duplication } \\
\text { and } \\
\text { confusion. }\end{array}$ & \\
\hline \multirow[t]{2}{*}{$\begin{array}{c}\text { There was no } \\
\text { activation } \\
\text { program. }\end{array}$} & & & & $\begin{array}{l}\text { Entering and } \\
\text { exiting of } \\
\text { ambulances was } \\
\text { very difficult, } \\
\text { because they } \\
\text { entered through } \\
\text { the same door as } \\
\text { patients and their } \\
\text { families. }\end{array}$ & & $\begin{array}{l}\text { All command } \\
\text { staff had been } \\
\text { called onto } \\
\text { the scene, } \\
\text { while they } \\
\text { should have } \\
\text { stayed in the } \\
\text { command } \\
\text { center. }\end{array}$ & \\
\hline & & & & & & $\begin{array}{l}\text { At first, the } \\
\text { hospital } \\
\text { personnel had } \\
\text { no familiarity } \\
\text { with the EOC } \\
\text { and its duties }\end{array}$ & $\begin{array}{c}\text { Over time, } \\
\text { the hospital } \\
\text { personnel } \\
\text { were } \\
\text { familiarized } \\
\text { with the } \\
\text { EOC and } \\
\text { its duties. }\end{array}$ \\
\hline
\end{tabular}

HICS: Hospital incident command system; ICS: Incident command system; EOC: Emergency operation center

From the perspective of the 4Cs (Table 2):

1. Coordination in ICS was satisfactory, but the duties of the manager of each section were not clear and this caused duplication and confusion.
2. There was no activation plan.

3. At first, the hospital personnel had no familiarity with the EOC and its duties, but after this incident, this problem was resolved. 
4. On the first day, measures were not taken according to the disaster management protocols of the hospital, but team coordination in all levels was satisfactory.

5. All command staff had been called onto the scene, while they should have stayed in the command center.

6 . The reporting and recording of the health team of the ICS was satisfactory.

7. According to the hospital protocols, the hospital incident command system (HICS) was not well coordinated.
8. There was no plan for management of VIPs such as representatives of the provincial governor and attorney, police, and the press and media, and this caused some problems in providing services.

9. The security department of the hospital functioned well, but entering and exiting of ambulances was very difficult because they entered through the same door as patients and their families.

Table 3: Characteristics of surge capacity from the perspective of 4Ss in the hospital

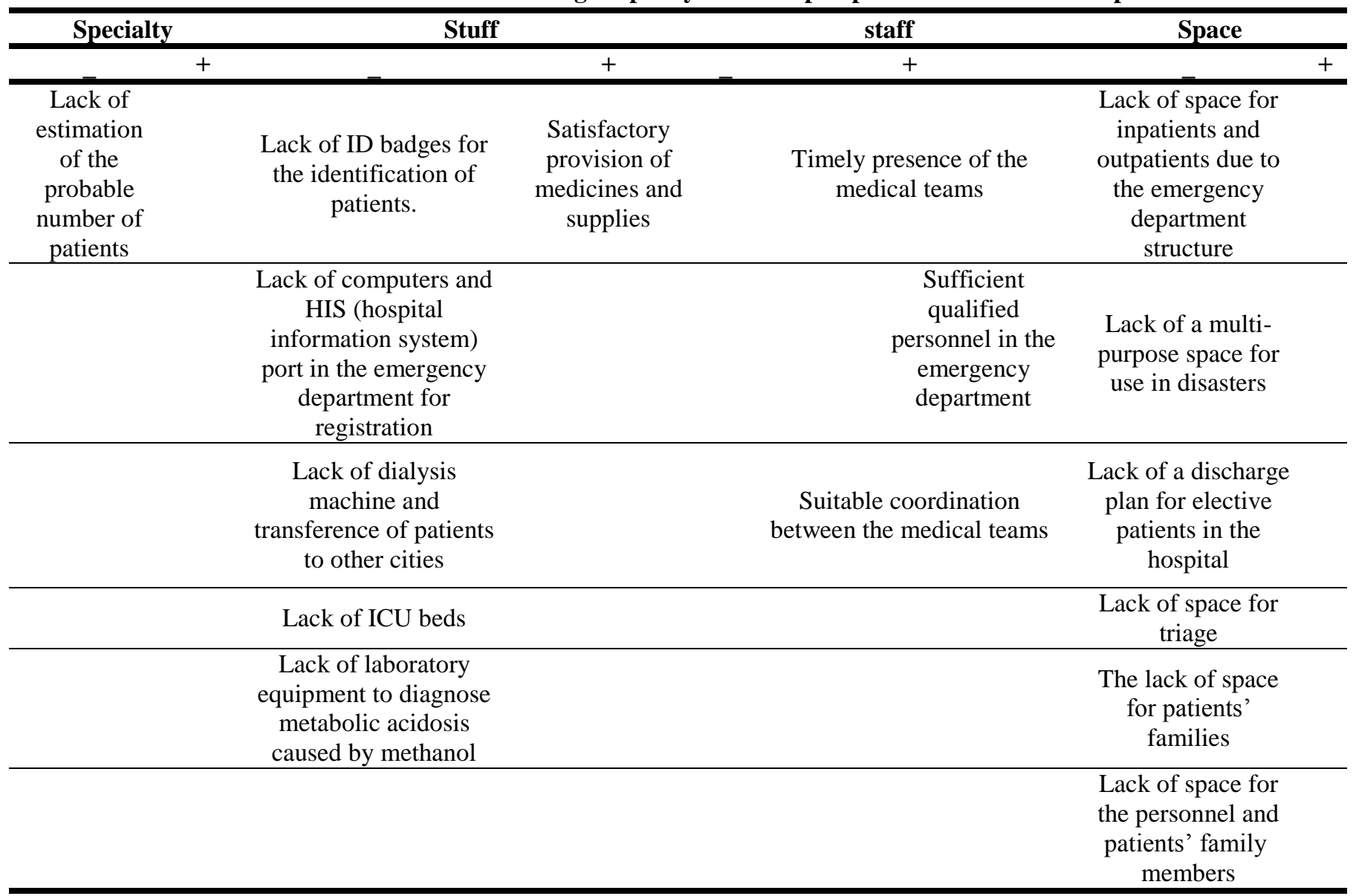

ICU: Intensive care unit

From the perspective of the 4Ss (Table 3):

1. Timely presence of the medical teams.

2. Sufficient qualified personnel in the emergency department
3. Suitable coordination between medical teams

4. Satisfactory provision of medicines and supplies 
5. Lack of ID badges for the medical team and incidence team

6. Lack of ID badges for identification of patients

7. Lack of computers and HIS (hospital information system) port in the emergency department for registration

8. Lack of dialysis machine and transference of patients to other cities

9. Lack of space for inpatients and outpatients due to the emergency department structure

10. Lack of ICU beds

11. Lack of a discharge plan for elective patients in the hospital

12. Lack of a multi-purpose space for use in disasters.

13. Lack of laboratory equipment to diagnose metabolic acidosis caused by methanol

14. Lack of space for triage
15. Lack of space for patients' families

16. Lack of space for the personnel and patients' family members

17. Lack of estimation of the probable number of patients

From the perspective of the 3Ts (Table 4):

1. Unsuitable triage of patients because of influx of patients and their families in the first hours (the problem was resolved with the transference of the triage space to outside the emergency department)

2. Failure to separate outpatient and inpatient admissions (the problem was resolved on the second day)

3. Failure to complete the registration of patients

4. Satisfactory transference and transportation in the pre-hospital phase

5. Timely performance of treatment of patients by the medical team

6. Satisfactory and fast transference of patients to other cities by ambulance and coordination

Table 4: Characteristics of surge capacity from the perspective of 3Ts in the hospital

\begin{tabular}{cccc}
\hline Transport & Treat & Triage & + \\
\hline $\begin{array}{c}\text { Satisfactory transference } \\
\text { and transportation in the } \\
\text { pre-hospital phase }\end{array}$ & $\begin{array}{c}\text { Timely } \\
\text { performance of } \\
\text { treatment of } \\
\text { patients by the } \\
\text { medical team }\end{array}$ & $\begin{array}{c}\text { Unsuitable triage of } \\
\text { patients because of influx } \\
\text { of patients and their } \\
\text { families in the first hours }\end{array}$ & $\begin{array}{c}\text { The problem was } \\
\text { resolved with the } \\
\text { transference of the triage } \\
\text { space to outside the } \\
\text { emergency department }\end{array}$ \\
\hline $\begin{array}{c}\text { Satisfactory and fast } \\
\text { other cities by ambulance } \\
\text { and coordination }\end{array}$ & $\begin{array}{c}\text { Failure to separate } \\
\text { outpatient and inpatient } \\
\text { admissions }\end{array}$ & $\begin{array}{c}\text { The problem was } \\
\text { resolved on the second } \\
\text { day }\end{array}$ \\
\hline
\end{tabular}

\section{Discussion}

Despite effective treatment of methanol poisoning, unfortunately its mortality rate is high (19). In Islamic countries, due to legal prohibition of the sale and distribution of alcohol, methanol poisoning is caused by handmade drinks. In Iran, methanol poisoning is becoming a serious problem for the health care system. The majority of consumers of alcoholic drinks are young individuals (18). On the other hand, because of Iran's religious and legal restrictions, the rate of alcohol poising is increased due to increased use of substandard alcohol $(18,20)$.

The methanol poisoning incident in Rafsanjan was an unexpected event for the city and the healthcare system. However, it must be considered, because of the probability of 
reoccurrence in other cities. Therefore, there are very valuable experiences in this incident from the perspective of HSC. In order to develop a disaster response plan in hospitals, the following steps should be taken: 1 . identifying the hospital to respond to the disaster; 2. determining the total number of patients, to which the hospital can provide services; 3. planning for training qualified staff for critical situations; 4. planning for equipment and supplies; 5. planning for the treatment area and the route for transporting the stretchers; 6. planning for the development of a family information center (FIC); 7. Creating a staff calling plan; 8, Creating the HICS; 9, Creating an activation plan; and 10, Planning for standard training (21). In this incident, due to unfamiliarity with the circumstances, the necessary measures could not be predicted, but many shortcomings were resolved quickly during the response.

Hospitals should have plans for spaces to accommodate an influx of victims and injured individuals. Spaces for triage, registration of patients, caring for patients, operation rooms for trauma and fracture cases, recovery rooms, and a decontamination center are necessary in hospitals. In all natural or manmade incidents, the demand for hospital services is increased; therefore, the HICS including incident commander and other posts in the command center should be activated. (22). In this incident, there was not enough space for triage. Coordination of EOC and ICS was not satisfactory, because the hospital personnel did not have any previous exercise.

In such incidents, the hospital manager should cancel some elective services, plan for discharging some patients to increase the number of available hospital beds, identify an alternate care site and external care site for transferring patients, maximize the capacity of medical triage and treatment, and install tents as required (8). To create an appropriate space for emergency department triage, some protocols should be developed such as a protocol for discharging patients or alternate care sites in the hospital like the conference hall and post-ICU unit, or outside the hospital like other hospitals or nursing homes. Alternative elective outpatient care spaces could be suitable for outpatient triage. First, all hospital spaces should be identified. In planning for surge capacity, spaces for family members and family support center, supportive care and patient tracking, media, satellite communication system, behavioral care unit, resting of staff and patients' families, and gathering of personnel are important. There was no plan before this incident, but the triage process was facilitated over time.

In order to overcome the shortage of human resources, the hospital manager should consider planning for staff surge capacity, job rotation, strategies for staff maintenance, planning for access to expert staff inside and outside the hospital, and planning for calling the staff (activation of an alert code). In this incident, there was no report of malfunction of EOC or calling of staff or failure in screening of metabolic acidosis in emergency departments (8, 18, 21). Active screening (encouraging patients to find their drinking partners in Rafsanjan via SMS and frequent broadcasting of messages and announcements via the local radio of Rafsanjan) was a valuable experience that can be used in similar events.

In order to coordinate, command, and control an incident, the hospital manager should integrate the principles of the incident management system in the hospital, develop manuals for different processes, improve coordination between hospitals and medical centers and emergency services, improve the compatibility of IMS with national strategies, plan for achieving resource and resource mobilization, develop a memorandum of understanding (MOU) with the main stakeholders about the hospitals contribution fund (HCF) (provide 
medical support, supplies, referral system, coordination, and etcetera) $(4,23)$.

Furthermore, providing survival equipment, maximizing all logistic and financial resources, providing blood and blood products and donors, sharing resources with private and public hospitals, providing protective equipment, procuring materials and equipment for all kinds of casualties, including airway, endotracheal intubation, ambo bags and masks, chest tube insertion devices, drugs such as diazepam and morphine, atropine, disposable devices like catheters clothes, reusable items such as beds, IV pumps, devices for measuring blood pressure, procuring materials and equipment to take care of patients who need specialized care, anti-bacterial drugs, intravenous fluids, needles for injection, special plaster for casting and etcetera, procuring personnel protection equipment, 'medications, antibodies, antivirus, vaccines, other risk reduction strategies such as ultraviolet rays, ventilator, and etcetera, providing water, food, supplies such as office desks, chairs, pencils, calculators, pens, erasers, sewing machines, and glue, communication devices such as telephone, fax, and mobile, and providing oxygen cylinders, manometer, masks, and etcetera are very important in preparing for surge capacity.

In surge capacity management, managers should plan for communication and coordination with private hospitals, recourse sharing, and access to external resources such as military services and the private sector (4). In this incident, due to lack of prediction, there was a lack of resources such as ICU beds and dialysis machine. Therefore, due to these shortcomings, many patients were transferred to other hospitals. External coordination with the police and other institutions was satisfactory, while the internal coordination had some problems. Each organization acted according to their protocol; thus, a unified command and reporting protocol are very important in such incidents.
A definition of public health is improvement of the quality of individual interaction with the community and the welfare of the society and the final result of this interaction is the promotion of social capital and social security, and reduction of poverty and inequality. Alcohol and drug abuse are social disorders and have negative impact on economic, social, cultural, and health systems (24). Hence, a comprehensive plan is required with the cooperation of other organizations in our society.

\section{Conclusion}

HSC in the event of methanol poisoning is inevitable. Thus, attention to this issue and preparation for it is very important in the response phase. In this regard, preparation of executive program, guidelines for exposure to a variety of incidents, determination of hospitals or medical centers and equipping them commensurate with threatening hazards, and personnel training can prepare hospitals to deal with these events. Moreover, designing and implementation of the maneuver, training skilled volunteers, coordination with other provinces through a systematic referral system, and other measures that can be implemented.

\section{Acknowledgements}

The authors wish to thank the ECO secretary of Rafsanjan University of Medical Sciences, the emergency staff of the Deputy of Health in Rafsanjan University of Medical Sciences, and all their colleagues at the university who assisted in the performance of this study.

Conflict of interests: None declared.

\section{References}

1. Bayram JD, Sauer LM, Catlett C, Levin S, Cole G, Kirsch TD, et al. Critical resources for hospital surge capacity: an expert consensus 
panel. Version 2. PLoS Curr 2013; 5. pii: ecurrents.dis.67c1afe8d78ac2ab0ea52319eb1196

88.

doi:

10.1371/currents.dis.67c1afe8d78ac2ab0ea52319 eb119688.

2. Adams LM. Exploring the concept of surge capacity. The Online Journal of Issues in Nursing 2009; 14(2).

DOI: 10.3912/OJIN.Vol14No02PPT03

3. Kaji A, Koenig KL, Bey T. Surge capacity for healthcare systems: a conceptual framework. Acad Emerg Med 2006;13(11):1157-9.

4. Traub M, Bradt DA, Joseph AP. The surge capacity for people in emergencies (SCOPE) study in Australasian hospitals. Med J Aust 2007; 186(8):394-8.

5. Hick JL, Hanfling D, Burstein JL, DeAtley C, Barbisch D, Bogdan GM, et al. Health care facility and community strategies for patient care surge capacity. Ann Emerg Med 2004; 44(3):253-61.

6. Hick JL, Barbera JA, Kelen GD. Refining surge capacity: conventional, contingency, and crisis capacity. Disaster Med Public Health Prep 2009; 3(2 Suppl):S59-67.

7. Roccaforte JD, Cushman JG. Disaster preparedness, triage ,and surge capacity for hospital definitive care areas: Optimizing outcomes when demands exceed resources. Anesthesio Clin 2007; 25(1):161-77.

8. Schultz $\mathrm{CH}$, Stratton SJ. Improving hospital surge capacity: a new concept for emergency credentialing of volunteers. Ann Emerg Med 2007; 49(5):602-9.

9. Hwang U, McCarthy ML, Aronsky D, Asplin B, Crane PW, Craven CK, et al. Measures of crowding in the emergency department: a systematic review. Acad Emerg Med 2011; 18(5):527-38.

10. Schull MJ. Hospital surge capacity: if you can't always get what you want, can you get what you need? Ann Emerg Med 2006; 48(4):389-90.

11. Einav S, Hick JL, Hanfling D, Erstad BL, Toner ES, Branson RD, et al. Surge capacity logistics: care of the critically ill and injured during pandemics and disasters: CHEST consensus statement. Chest 2014; 146(4 Suppl):e17S-43S.

12. Bonnett CJ, Peery BN, Cantrill SV, Pons PT, Haukoos JS, McVaney KE, et al. Surge capacity: a proposed conceptual framework. Am J Emerg Med 2007; 25(3):297-306.

13. Unsal A, Basturk T, Sakac T, Ahbap E, Koç Y,
Yilmaz M. Epidemic acute methanol intoxication as a result of illicit alcohol ingestion. Nephrourol Mon 2012; 4(1):366-71.

14. Shadnia S, Rahimi M, Soltaninejad K, Nilli A. Role of clinical and paraclinical manifestations of methanol poisoning in outcome prediction. J Res Med Sci 2013; 18(10):865-9.

15. Sanaei-Zadeh H, Esfeh SK, Zamani N, Jamshidi F, Shadnia S. Hyperglycemia is a strong prognostic factor of lethality in methanol poisoning. J Med Toxicol 2011; 7(3):189-94.

16. Geographical Info of Rafsanjan city in Kerman province [Internet]. [This page was last modified on 2 November 2015, at 14:17. Cited 20155 march].

Available from: https://en.wikipedia.org/wiki/Rafsanjan_County

17. The introduction of Ali ebn-Abi-Talib (AS) hospital wards and their duties [Internet]. [updated 2015 Feb 10 cited 5 December 2015] Available from: http://aliebn.rums.ac.ir

18. Hassanian-Moghaddam H, Nikfarjam A, Mirafzal A, Saberinia A, Nasehi AA, Masoumi Asl H, et al. Methanol mass poisoning in Iran: role of case finding in outbreak management. J Public Health (Oxf) 2015: 37(2):354-9.

19. Akhgari M, Panahianpour MH, Bazmi E, Etemadi-Aleagha A, Mahdavi A, Nazari SH. Fatal methanol poisoning: features of liver histopathology. Toxicol Ind Health 2013; 29(2):136-41.

20. Hassanian-Moghaddam H, Pajoumand A, Dadgar SM, Shadnia Sh. Prognostic factors in methanol poisoning. Hum Exp Toxicol 2007; 26(7):583-6.

21. Lynn M, Gurr D, Memon A, Kaliff J. Management of conventional mass casualty incidents: ten commandments for hospital planning. J Burn Care Res 2006; 27(5):649-58.

22. Nager AL, Khanna K. Emergency department surge: models and practical implications. J Trauma 2009; 67(2 Suppl):S96-9.

23. Zenteno Langle AC. Models for managing surge capacity in the face of an influenza epidemic. [PhD thesis]. New York, United States of America: Columbia University; 2012.

24. Haghdoost AA, Emami M, Esmaili M, Soberinia A, Nezhad Ghaderi M, Mehrolhassani MH. Survey the status and causes of alcohol consumption: a case study of the epidemic alcohol poisoning in Rafsanjan in 2013. Journal of Rafsanjan University of Medical Sciences 2015; 13(10):991-1006. 